\title{
New problems and opportunities of oil spill monitoring systems
}

\author{
GRIGORY M. BARENBOIM ${ }^{1}$, VLADIMIR M. BORISOV ${ }^{2}$, \\ VALENTIN N. GOLOSOV ${ }^{3} \&$ ALEXANDR Yu. SAVECA ${ }^{1}$ \\ 1 Institute of Water Problems of Russian Academy of Sciences, Gubkina ul. 3, 119333 Moscow, Russia \\ gbarenboim@gmail.com \\ 2 Troitsk Institute for Innovation \& Fusion Research, Pushkovykh ul. 12, Troitsk, 142190 Moscow, Russia \\ 3 Lomonosov Moscow State University, GSP-1, Leninskie Gory 1, 119991 Moscow, Russia
}

\begin{abstract}
Emergency oil and oil products spills represent a great danger to the environment, including ecosystems, and to the population. New problems of such dangerous spills and methods of early detection are discussed in this paper. It is proposed to conduct assessment of biological hazards of such spills on the basis of data on the distribution of individual oil hydrocarbons within the column of the water body and computer predictions of their toxicity. Oil radioactivity, which is associated with uranium and thorium, is seen as the important aspect of the oil spill danger, especially in watercourses. The need for an automated monitoring system for the early detection of oil spills in water bodies is analysed. The proposed system consists of three subsystems. The first remote sensing subsystem is based on powerful fluorescent lidars; experimental results on lidar registration of oil pollution of water are reported. The second subsystem uses a network of automatic monitoring stations with contact detectors. The third subsystem is the combined sensor system based on remote and contact technologies.
\end{abstract}

\section{INTRODUCTION}

One of the daunting problems of modern environmental science is the pollution of aquatic ecosystems by oil and oil products (gasoline, kerosene, fuel oil, etc.), which suppresses the vital functions of flora and fauna and makes the water body hazardous for use as a drinking water supply. The urgency of this problem is determined by the current operational and developmental scales of the oil industry (production, storage, transport, processing), which is accompanied by the increase of oil spills. According to the National Report on Environmental Protection of the Russian Federation, in 2010 in Russia there were about 27000 pipeline crashes (including field and infield pipelines; National Report 2009). Regular crashes of the oil tanker fleet and ships with other functions take place on the inland waterways. In 2002-2007 on just the Neva River there were on average about 20 oil spills per year (Barenboim et al. 2009). Generally, each region of Russia is subjected to spills of oil or oil products: there are the routes of oil transport (pipeline, shipping or rail) in regions where there is no production or processing of oil; and there are fuel and lubricants depots and the means for their delivery in all regions.

The risk of oil spills in Russia is increasing due to the development of new operational oilfields, and further increases to the total volume of oil production and processing are being planned: the Baltic pipeline system is being expanded, construction of an oil pipeline from Eastern Siberia to the Far East, with a branch in China is being completed, the project of pipeline transport of oil from Western Siberia to Murmansk is being considered, the programme of oil transportation through the Northern Sea Route by tankers of an icebreaking type is being run in pilot mode, an ice-resistant offshore oil platform has been mounted in the Barents Sea, and so on.

It should be considered that the large-scale oil spills are the most significant since they can exert long-term and destructive influence on the environment, including biota, and sometimes on the population and agricultural facilities. For example, one of the largest oil spills on land, which occurred in the Komi Republic in 1994 (100 000 tons of oil and 100000 tons of wastewater), has resulted in contamination of about 253 hectares of land. About $45 \mathrm{~km}$ of access roads, $5.5 \mathrm{~km}$ of dams and localization dikes were built for elimination of the consequences. Some parts of the oil pollution, which could not be localized with booms and dams on streams, has broken into the Pechora River, which flows into the Barents Sea of the Arctic Basin (Barenboim et al. 2013a). The World Bank jointly with the European Bank for Reconstruction and Development have allocated about US\$124 million (Barenboim et al. 2000, 2006), which by expert calculations was less than $50 \%$ of the total cost for emergency elimination. 
The oil industry operations (production, transportation, stowage, refining) are often accompanied by an oil ingress into the environment. Oil spills due to accidents of tankers, pipelines and offshore platforms, are well known and will not be discussed here. We just consider one example that demonstrates the change in the number of pipe leaks in Russia (Fig. 1).

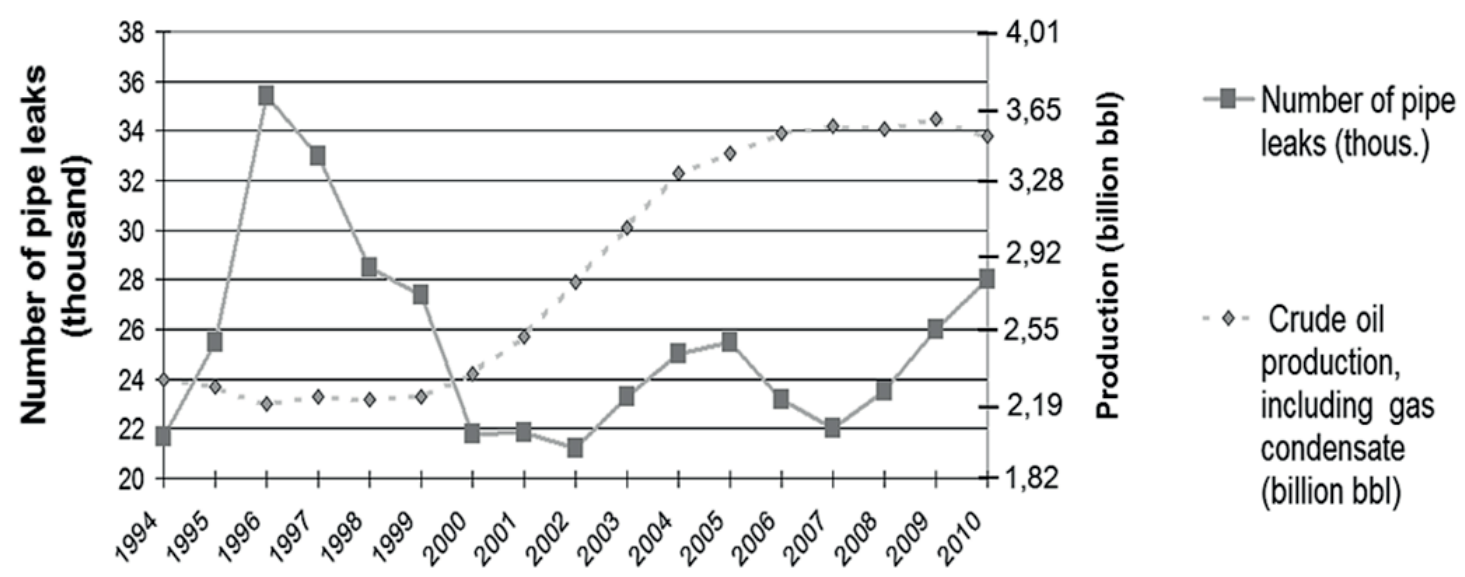

Fig. 1 Crude oil production and number of pipe leaks in Russia (Blokov 2011).

\section{TRANSFORMATION OF OIL UNDER ACCIDENTAL OIL SPILLS IN WATER}

From the chemical point of view, oil is a complex mixture of organic compounds, most of which are hydrocarbons (HC) of different chemical classes; current data show that oil can include over 2000 individual HC. Its composition also includes heteroatom compounds, some metals, among which the most dominant are vanadium and nickel, natural radionuclides (uranium, thorium and their radioactive families, including radium), and other chemical elements.

When oil gets into water it ceases to exist as a mixture of its components as a result of various chemical, physicochemical and metabolic transformations, produced (in the last case) by hydrobiota (Barenboim and Saveka 2012). As a result of the above mentioned processes, the oil spilled in water is represented by different combinations of individual $\mathrm{HC}$, by the original (primary) $\mathrm{HC}$ and by their transformation products (secondary) at different vertical levels in the water body and bottom sediments. Consequently, toxicity (intensity and types of toxicity) distributes over the water body depth irregularly depending on its physical and chemical properties.

Due to oil ingress into the aquatic environment, the following processes may occur:

- Formation of surface slicks

- Evaporation

- Settling

- Sorption onto suspended matter and bed sediments

- Emulsification ("oil-in-water", "water-in-oil”)

- Dissolution

- Catalytic destruction

- Photochemical transformations

- Oxidation

- Polymerization

- Complexing with metals

- Microbiological transformation

- Macrobiological transformation

With the distribution of $\mathrm{HC}$ in water bodies (for example, in a river) the structure of these combinations changes qualitatively and quantitatively. Some examples are given below to confirm the above provisions. 
In addition, the concentrations of specific groups of $\mathrm{HC}$ in water vary in different ways. For example, in water samples taken on the Pechora River (distance between sampling sites is approximately $120 \mathrm{~km}$ ), the concentration $\mathrm{HC}$ with $\mathrm{C}_{7}-\mathrm{C}_{8}$ has undergone minor changes within the same oil slick, the migration of which was monitored by a special technique, while the concentrations of some HC decreased by 140 times (Table 1; Barenboim et al. 2000).

One study analysed the consequences of an oil spill in the underwater river part of the pipeline in the winter period; it resulted in about 1000 tons (approx. 7300 barrels) of oil being incorporated into the large laminar flow. In addition, the content of different $\mathrm{HC}$ groups was estimated at various distances from the spill site and at different depths. The proportion of aromatic and paraffinic oil components dissolved in the surface layer of water $(0.5 \mathrm{~m})$ below the accident site was close to the their ratio in oil. In the deep layers of the watercourse $(4 \mathrm{~m})$, the dissolved oil was depleted in the aromatic fraction. The maximum content of dissolved alkanes and arenes in the surface layer of water was observed at a distance of $20 \mathrm{~km}$ from the accident site, and in the deep layers at $8 \mathrm{~km}$ distance (Fig. 2; Safarov et al. 2005).

Table 1 Content of some oil components in water samples of a migrating spot for sampling at various distances (Pechora River, August 1997).

\begin{tabular}{llll}
\hline Component & \multicolumn{2}{l}{ Concentration $(\mathrm{mg} / \mathrm{L})$} & Ratio \\
& Sample 1 & Sample 2 & Sample 1/Sample 2 \\
\hline Hydrocarbons C6 & 0.0006 & 0.0028 & 0.21 \\
Hydrocarbons C7-C8 & 0.0031 & 0.0028 & 1.11 \\
Hydrocarbons C9-C10 & 0.0008 & $<0.0001$ & $>8.00$ \\
Hydrocarbons C11-C12 & 0.0006 & $<0.0001$ & $>6.00$ \\
Hydrocarbons C13-C14 & 0.0140 & $<0.0001$ & $>140.00$ \\
Hydrocarbons C15-C16 & 0.0680 & 0.0128 & 5.31 \\
Hydrocarbons C17-C20 & 0.0700 & 0.0150 & 4.67 \\
\hline$\sum$ HC & 0.1570 & 0.0035 & 4.49 \\
\hline Individual compounds & & & \\
Benzene & 0.0020 & 0.0008 & 2.50 \\
Toluene & 0.0060 & 0.0030 & 2.00 \\
Xylenes & 0.0090 & 0.0011 & $>8.18$ \\
Ethylbenzene & 0.0011 & $<0.0001$ & 11.00 \\
Naphthalene & $<0.001$ & 0.0003 & $<3.30$ \\
\hline
\end{tabular}

\section{PREDICTION OF BIOLOGICAL ACTIVITY OF OIL HYDROCARBONS}

Water pollution by oil or oil products makes these waters toxic. The behaviour of oil in water, as discussed above, suggests that toxicity of water in different parts of the water body differs horizontally and vertically, and is determined by specific individual HC in each such area. However, in many countries, including Russia, the safe level is determined by an official regulatory value of maximum permissible concentration (MPC) for total petroleum HC. In Russia, MPC is represented by the so-called "MPC for oil products", which is defined as hydrophobic HC, definitely soluble in organic solvents, in this case, in hexane. It is obvious that this standard relates to a particular group of $\mathrm{HC}$ in general. It does not take into account the toxicity specific to all individual $\mathrm{HC}$ that can also be transformed in the water abiotically or biotically.

The MPC for individual $\mathrm{HC}$ is also rationed, but the number of normalized $\mathrm{HC}$ is small (in Russia no more than 50), whereas oil contains more than 2000 hydrocarbons, and their transformation in water increases the number. Obviously, the concentration and dose characteristics that match the safe level of individual $\mathrm{HC}$ exposure in vivo are presented only for a limited number of HC. Data/standards are almost completely unavailable for the secondary products of chemical transformations of $\mathrm{HC}$.

Determination of MPC for all petroleum HC is a costly, time-consuming task and, considering the variety of derivatives, it is practically impossible. In this context we have examined the 

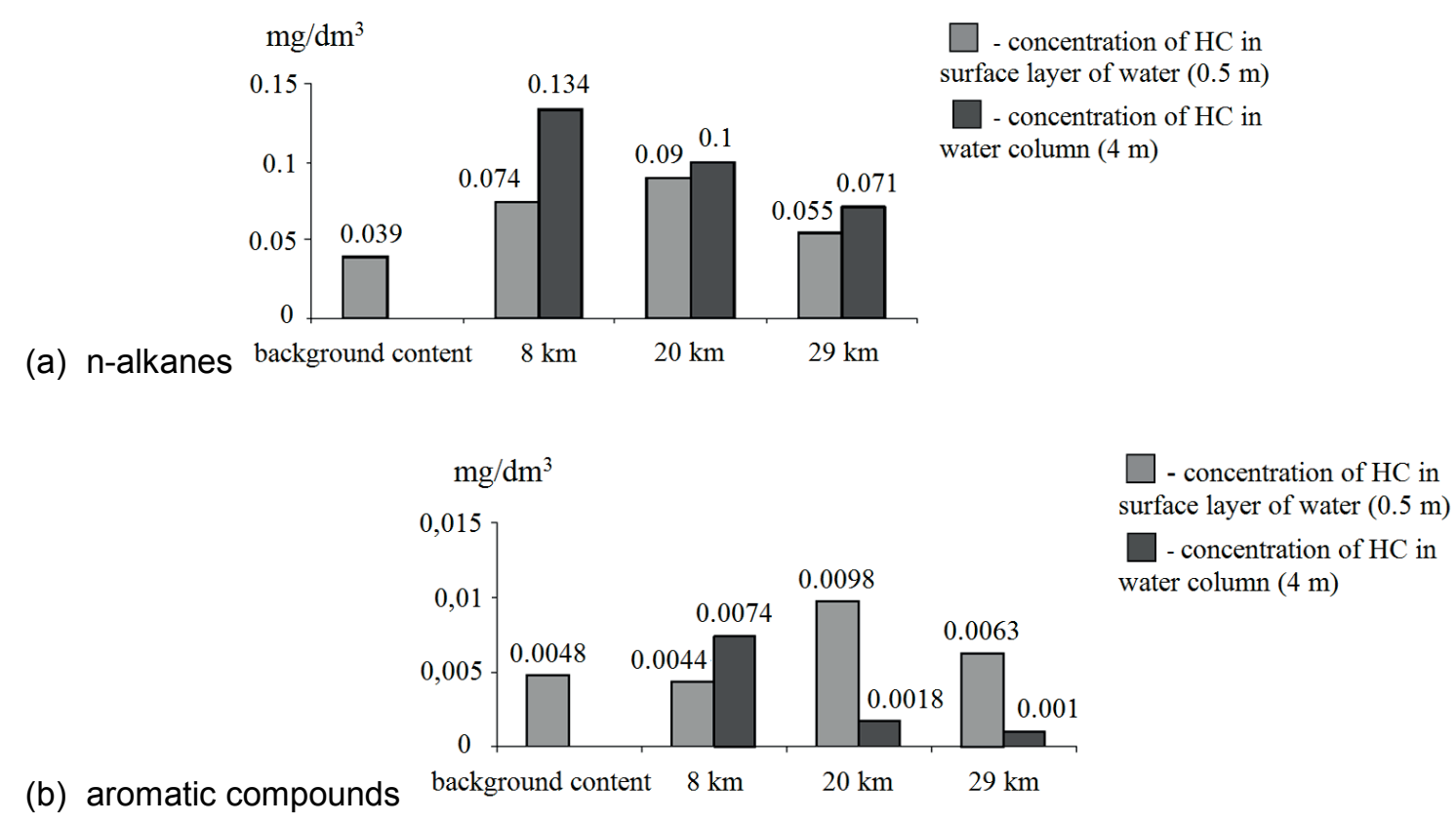

Fig. 2 Distribution of dissolved n-alkanes (a) and arenes (b) at different distances from the accident site.

possibility of computational determination of biological activity (BA), including toxicity, for each individual $\mathrm{HC}$, depending on its chemical structure. Such an approach not only provides information about MPC but allows classification of HC of oil and petroleum products, as well as their primary and secondary products and their metabolites (etc.), by the type of activity, highlighting, for example, mutagens, carcinogens, hemo- and hepatotoxins, etc. This allows more realistic assessment of the biological hazard of spill and environmental risks.

This approach is fundamentally possible because of two facts:

- modern analytical techniques, primarily chromatography/mass-spectrometry, enable us to determine petroleum $\mathrm{HC}$ in low concentrations and to establish their structure; and

- methods to predict the structure of BA have been intensively developed over the last quartercentury, mostly in connection with the creation of new drugs, although these methods have not previously been used to establish BA of petroleum HC.

In addition, some information on the $\mathrm{BA}$ of some $\mathrm{HC}$ can be obtained from international databases.

The finding of information on the toxicity of individual $\mathrm{HC}$ in databases and by computational methods (structure-activity), were combined into a single system, known as the 'search and computational information system'. Major databases included in the search part of the system, for example, are the Russian database of hazardous chemical and biological compounds, International Chemical Safety Cards (ICSCs), ChemExper Chemical Directory, Comparative Toxicogenomics Database (CTD), databases of Joint Expert Committee on Food Additives (JECFA), Joint Meeting on Pesticide Residues (JMPR), International Agency for Research on Cancer (IARC), and the Agency for Toxic Substances and Disease Registry (ATSDR).

Currently, there are different methods to evaluate theoretically the BA of compounds. In this study, we used the method of analysing the "structure-activity relationship" and descriptive analysis by the training sample method that was implemented in a computer program PASS (Poroikov and Filimonov 2005, 2006).

The modern version of the computer program PASS 10.1 predicts more than 4000 types of BA, with an average accuracy higher than $95 \%$ (sliding control with the exception of one). The training sample program PASS 10.1 contains information on more than 260000 medical products and biologically-active compounds, including data on some chemical toxicants. 
The training sample is compiled from the experimental test results of BA chemical compounds on various biological objects with different hierarchical levels of complexity (both man and microorganisms). The output results, in addition to the names of BA, include assessment of probable presence $(\mathrm{Pa})$ and absence of each activity $(\mathrm{Pi})$, with values from 0 to 1 . Since these probabilities are computed independently, their sum is not equal to one. $\mathrm{Pa}$ and $\mathrm{Pi}$ are interpreted as estimated measures of the substance belonging to classes of active and inactive compounds, respectively. If the value of $\mathrm{Pa}$ is higher for a specific activity, and the value of $\mathrm{Pi}$ is lower, the chance of detecting this activity in the experiment is higher.

The PASS program informs the user about the available experimental substance values for various types of activity if the analyte is already in the training set. Detection probability in this case is not specified.

The program version used allows classification of activities by grades: (1) toxicity -57 activities; (2) macroeffects (including pharmacological effects) - 501 activities; (3) biochemical mechanisms of action - 3295 activities; (4) transformation of compounds in terms of metabolism 199 activities; (5) effects on gene expression - 29 activities; and (6) effects on proteins, transporters -49 activities. In this study, computations are limited to only the first two classes.

The presence of an organic compound with pharmacological activity does not mean that it is a drug: the negative properties can be significantly stronger than the positive. However, knowledge of the pharmacological activity can point to some of the targets in the body, as well as help determination of the operating range of doses for these targets.

$\mathrm{HC}$ are also present in those water bodies where there are no significant oil spills: $\mathrm{HC}$ release into these water bodies is often as pollution from petroleum products, although we should not exclude the natural output of individual $\mathrm{HC}$ in water. As an example, Table 2 shows BA prediction results of some petroleum $\mathrm{HC}$ for which there are no national regulations limit values, and which are found in the Ivankovskoe, Istrinskoe and Cheboksarskoe reservoirs of the Volga River basin and water intakes in the area allocated for treatment of drinking water.

Another possible application of the suggested approaches is the development of ecotoxicological maps, which allow outlining of the areas of a reservoir or a sea shelf, with notes of the type of toxic hazards of compounds present at the given sampling point. For example, ecotoxicological maps of Ivankovo Reservoir (Russia, the Volga basin) were developed around the points where samples of bottom sediments were taken, in which $\mathrm{HC}$ were identified. The results of such identification and localization of particular $\mathrm{HC}$ (generally polycyclic aromatic hydrocarbons or PAHs, see Fig. 3) have been discussed by Nemirovskaya et al (2009). Transformation of these data into toxicological forecasts was performed by the authors of this paper (Fig. 4).

\section{RADIOACTIVITY OF OIL AND PRODUCED WATERS}

As is generally known, the essential feature of oil pollution is the presence of heavy metals and natural radionuclides (known as naturally occurring radioactive materials, or NORM), which increases the environmental risks associated with the spill. Uranium $\left({ }^{238} \mathrm{U}\right)$ and thorium $\left({ }^{232} \mathrm{Th}\right)$ isotopes and the daughter isotopes of their radioactive families (e.g. ${ }^{226} \mathrm{Ra},{ }^{228} \mathrm{Ra},{ }^{222} \mathrm{Rn}$ ) are contained in oil and produced water at concentrations that significantly exceed background levels in the environment.

Contamination of water and bottom sediments can occur as a result of oil spills. This fact, in particular, is used for detection of oil pollution by the use of measurement with automated monitoring stations. Given the fact that NORM are found in heavy oil fractions, deposited to the bottom sediments after the spill, special attention should be paid to them during post-emergency monitoring. Radionuclides have the capability to accumulate in living organisms and of trophic transfer. The half-life of certain isotopes may be tens of thousands of years (e.g. half-life of ${ }^{226} \mathrm{Ra}$ is 1600 years), and hence radioactive contamination may be a long-term consequence of oil spills. This is usually not taken into account by post-emergency monitoring.

In one study carried out by the authors of this paper the contamination of bottom sediments in the Sura River (tributary of the mid-Volga region) above and below (downstream) the zone, where 
Table 2 Results of the computation of biological activity in some toxic hydrocarbons, for which there are no Russian limit values (at $\mathrm{Pa}>0.5$ ).

\begin{tabular}{|c|c|c|c|}
\hline No. & Detected substance & $\begin{array}{l}\text { Biological activity } \\
\text { Prediction of toxic activities } \\
\text { and probability of their } \\
\text { occurrence }\end{array}$ & $\begin{array}{l}\text { Pharmacological activities and } \\
\text { probability of their occurrence }\end{array}$ \\
\hline 11 & Fluoranthene & $\begin{array}{l}\text { 0.771 Carcinogenic, group } 1 \\
0.770 \text { Carcinogenic, group } \\
\text { 2A } \\
0.723 \text { Neurotoxic } \\
\text { 0.704 Thrombocytopoiesis } \\
\text { inhibitor } \\
0.703 \text { Hypercholesterolemic } \\
0.686 \text { Hyperthermic } \\
0.674 \text { Depression }\end{array}$ & $\begin{array}{l}0.793 \text { Immunostimulant (HIV) } \\
0.743 \text { Kidney function } \\
\text { stimulant } \\
0.734 \text { Immunomodulator (HIV) } \\
0.606 \text { Ovulation inhibitor }\end{array}$ \\
\hline 22 & Tetradecane & $\begin{array}{l}0.846 \text { Thrombocytopoiesis } \\
\text { inhibitor } \\
0.767 \text { Emetic } \\
0.752 \text { Neurotoxic } \\
0.751 \text { Hyperthermic } \\
0.701 \text { Depression } \\
0.629 \text { Convulsant } \\
0.605 \text { Eye irritation, moderate }\end{array}$ & $\begin{array}{l}\text { 0.901 Anti-inflammatory, } \\
\text { pancreatic } \\
0.874 \text { Immunostimulant (HIV) } \\
0.847 \text { Spermicide } \\
0.820 \text { Leukopoiesis stimulant } \\
0.810 \text { Immunomodulator (HIV) } \\
0.741 \text { Antimutagenic } \\
0.629 \text { Ovulation inhibitor }\end{array}$ \\
\hline
\end{tabular}

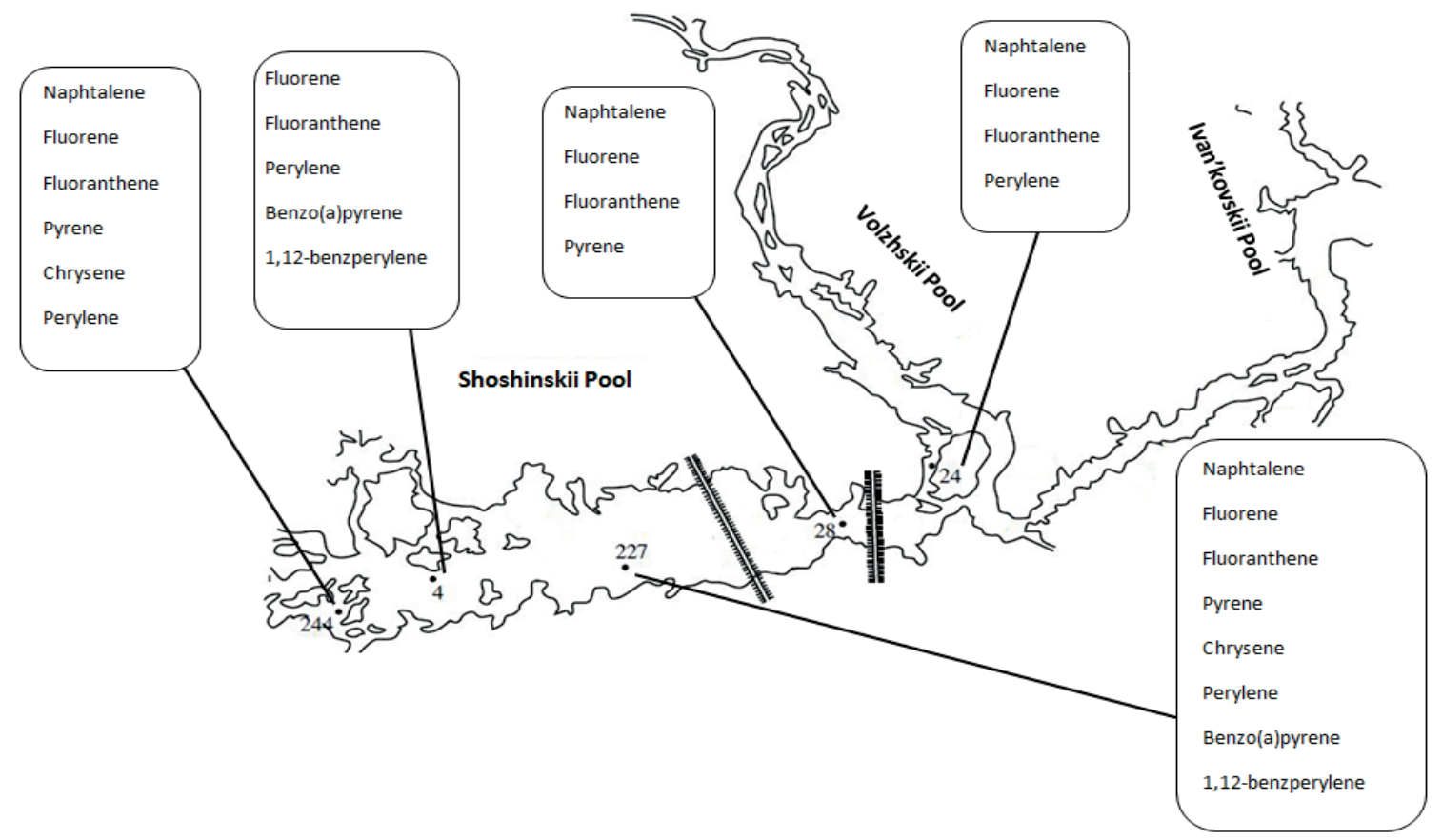

Fig. 3 Distribution of some PAHs in bottom sediments of Ivankovo Reservoir (on stations of sampling) (Nemirovskaya et al. 2009).

the main pipeline crosses the river, was investigated. The results are shown in Fig. 5. The results of radioactivity measurements of bottom sediments have shown that the values of radioactivity are significantly higher at the observation post located downstream of the branches of the pipeline than at the post located above. That increase of radioactivity downstream of the branches of the pipeline can be considered as indirect evidence of diffuse leakage of oil from the pipeline.

This can be considered as radioactive pollution and an additional long-term toxicological hazard for aquatic organisms due to the low solubility of heavy oil fractions in water, slow decay 


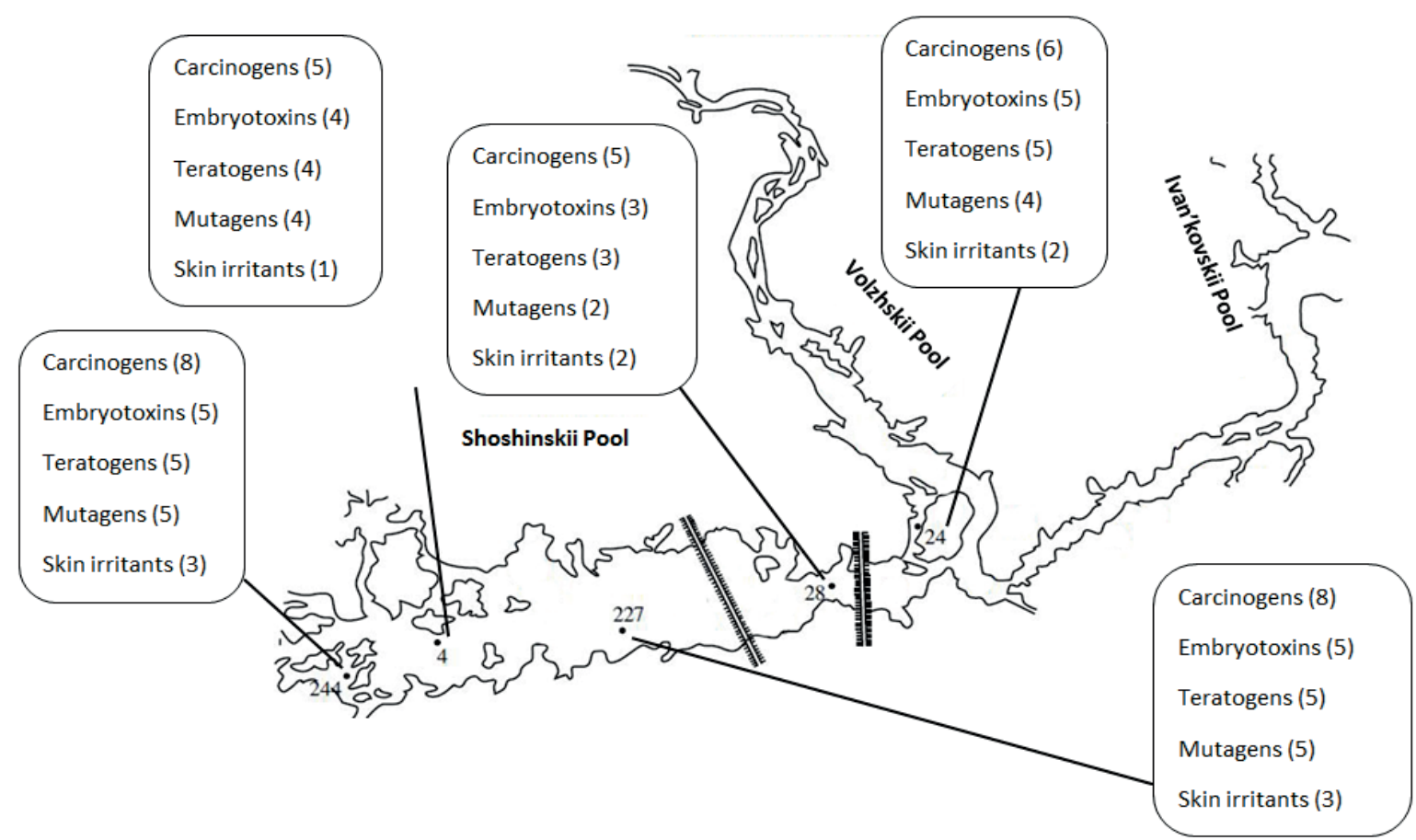

Fig. 4 Toxic hazard of some PAHs, founded in bottom sediments of Ivankovo Reservoir (on stations of sampling).

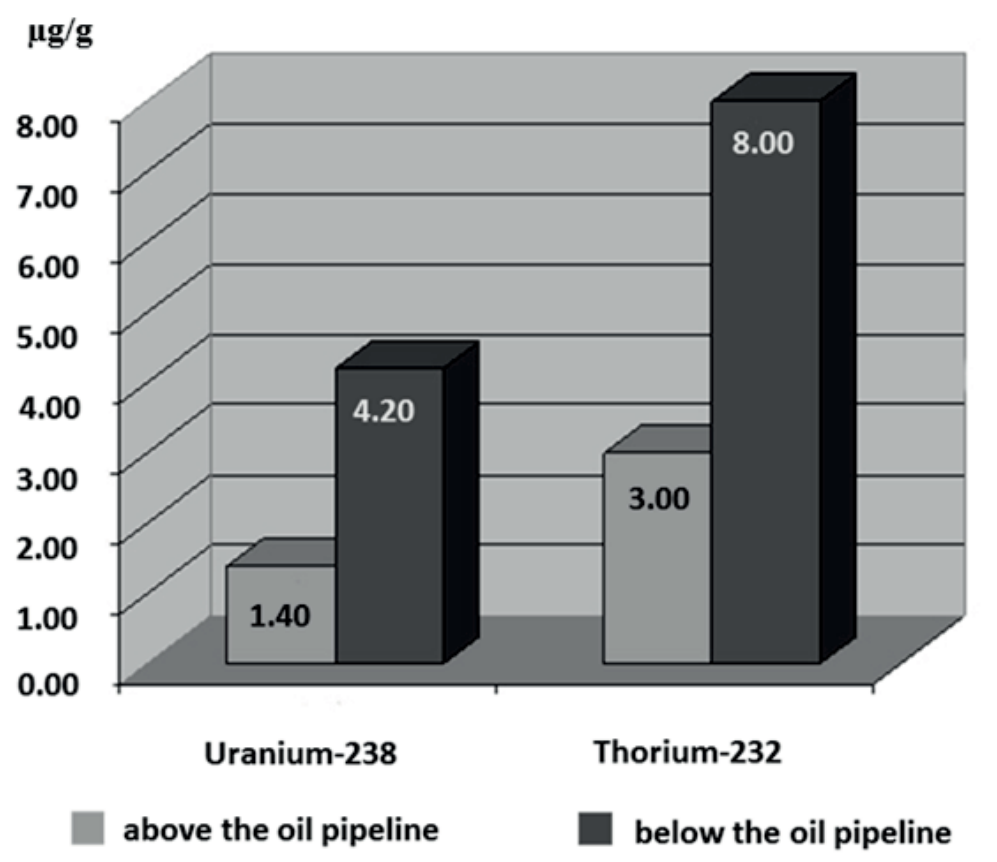

Fig. 5 Uranium and thorium content in bottom sediments above and below the oil pipeline (downstream).

time of $\mathrm{U}$, Th and Ra, and the ability to accumulate in bottom sediments for years. In the north of the European part of Russia (Komi Republic) there are areas where wastewater from oil processing was dumped, which has led to their unsuitability for agricultural use due to the high radioactivity. In turn, such areas are a source of radioactivity contamination of ground and surface waters. Our own and published data indicate that this aspect should be taken into consideration by emergency and post-emergency oil spill monitoring. 
The problem of transport of radioactive contamination associated with oil spills in water bodies requires environmental risk assessment. Experiments show that this transfer takes place in an aqueous medium, but is mainly due to the movement of sediments. Methodologies for the study of such transfer of radioactive substances are considered in detail by Belyaev et al. (2013) and Golosov (2013).

\section{MONITORING OF OIL POLLUTION INCLUDING ACCIDENTAL SPILLS OF OIL}

Fluorescent lidars According our studies there is no universal device or method that would make it possible to solve completely the problem of the early detection, emergency and postemergency oil spill monitoring. For oil spill detection, fluorescent lidars (FL) have many advantages.

Monitoring with use of FL is based on the measurement and interpretation of fluorescence spectra, remotely induced in the test object by monochromatic laser radiation. FL sensors investigate the surface of water with light pulses from an ultraviolet (UV) laser, for example in the UV spectral region, and analyse the spectrum of the signal of fluorescent radiation received from the probed surface in a longer-wave spectral region. The measured spectrum includes a combination of the fluorescent responses of the individual components presented in the sample. Since the spectral composition of the fluorescent response is related to the molecular structure of the object, the analysis of the fluorescence spectra makes it possible to identify substances and to evaluate their concentration in the object in some cases.

Unlike other methods, FL can detect the presence of oil on any surface, but also under the surface up to a certain layer thickness (e.g. in water, ice, snow). Because of several limitations for the FL application in specific conditions (e.g. large ice thickness), the combined system of remote and contact type detectors can be used. The main features of FL are: the possibility of high speed sensing, high sensitivity, day and night operation and analysis of data in both real-time operation and post-processing mode, and the ability of air, ship and stationary installation. Some results of these experiments are shown in Figs 6-8.

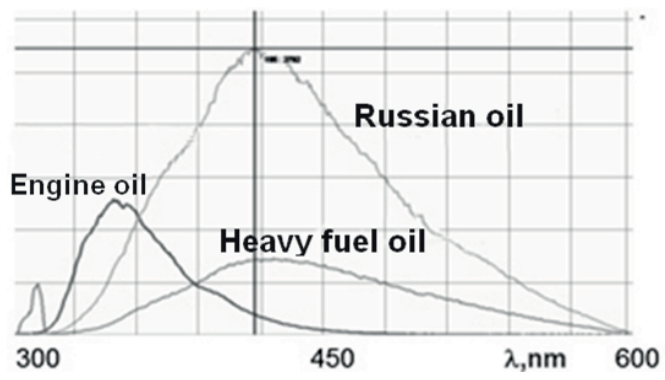

Fig. 6 Laser-induced fluorescence (LIF) spectra of petroleum products. Russian oil is a mixture of crude oil from different Russian oilfields.

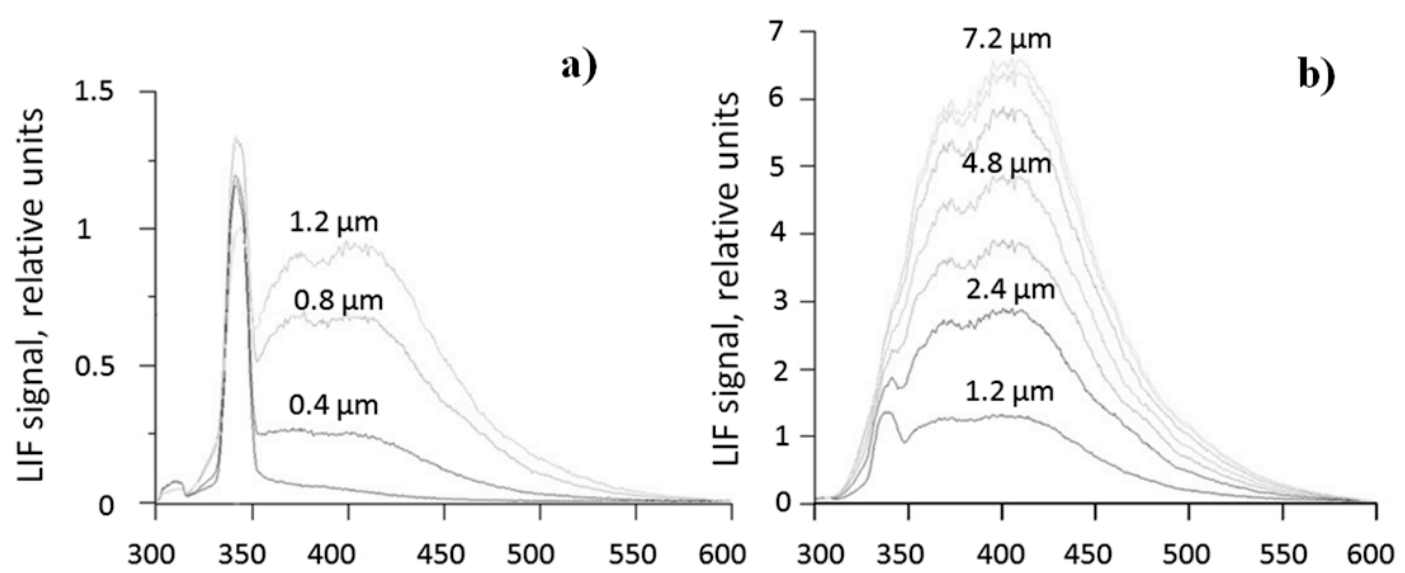

Fig. 7 LIF spectra of water with different oil film thickness: (a) 0 to $1.2 \mu \mathrm{m}$; and (b) 1.2 to $7.2 \mu \mathrm{m}$. 


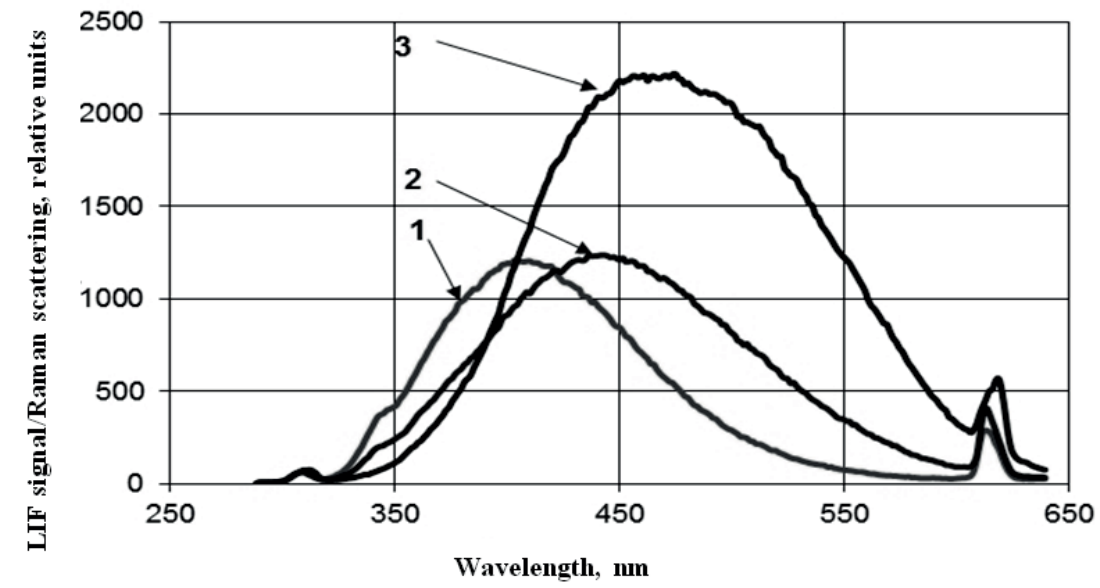

Fig. 8 LIF spectra of oil on the ice surface: 1 - clear ice; 2 - thin spots of oil on the ice surface (diameter of the spot $\sim 1 \mathrm{~mm}$ ); 3 - thin layer of oil on the ice surface.

Automated monitoring stations The problem of early detection of oil spills and the problem of emergency and post-emergency monitoring of inland surface waters is much more complicated when these waters are in periodic ice conditions with a significant thickness of ice. The rivers of the European North of Russia, Eastern and Western Siberia and the rivers of Central Russia occur in areas of low temperatures and are also exposed to the risk of oil spills.

The vast majority of remote sensing methods used in these cases are ineffective, so these authors have developed an oil spill monitoring system, the measurement part of which consists of FLs and automated monitoring stations (AMS) of the contact type that can be deployed either in a floating or in a submerged (under the ice) position. A specialized AMS was developed for creation of an automated system for early detection and monitoring of oil spills without remote sensing. The AMS (Fig. 9) includes a sealed container (buoy), which allows its placement both on the water surface and in an underwater position, and a set of sensors that contact with the water and measure its hydrological parameters (depth, current velocity, direction of current), oil pollution parameters (HC content - dissolved and emulsified forms, radioactivity, conductivity), and some parameters influencing the transformation of oil hydrocarbons in water (temperature, $\mathrm{pH}$, Eh, concentration of dissolved oxygen, turbidity).

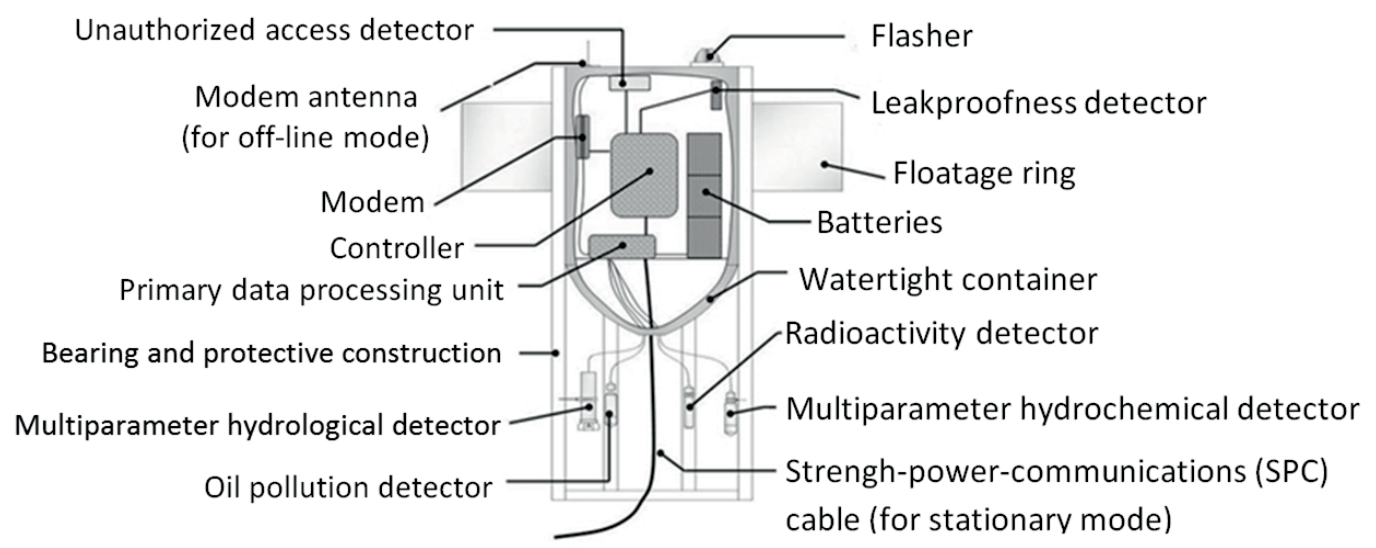

Fig. 9 Automated monitoring station (AMS) in sectional view.

Combined sensor system based on remote and contact technologies There is another version of the automatic monitoring system with a set of sensors in contact with water and measuring the parameters of the water quality. One of its distinguishing features is that the compact FL is mounted inside a sealed submersible (under the ice) container separate to the selfcontained power supply system and programmable controller with the system of collection, 
preprocessing and transfer of data. In addition this sealed container has an optical window, transparent to the probe and backscattered radiation, and equipped with a cleaning brush and a screen that minimize light exposure (Fig. 10; Avandeeva et al. 2014).

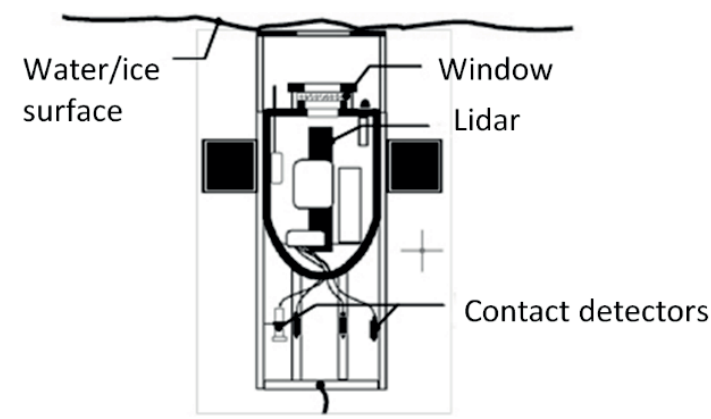

Fig. 10 Combined measuring system (lidar and contact sensors).

\section{CONCLUSION}

Water pollution associated with large-scale oil spills and oil products leads to environmental emergencies with grave consequences for hydrobiota (and in some cases for other types of biota) and possibly to the population, if the sources of drinking water are contaminated.

Application of the search and computational information system presented in this study makes it possible to evaluate the biological activity of individual petroleum hydrocarbons, and their secondary products, which are formed under the influence of environmental factors, if their chemical structure is known. In some cases, information on the maximum allowable concentrations or doses that are not provided by computation according to the 'structure-activity relationship', can be found in the databases presented in the system. Knowledge about the presence of substances with known types of toxicity (e.g. mutagenic, carcinogenic, hepatotoxic) allows the more accurate management of environmental risks in the process of mitigating oil spill consequences, as well as predictions to demonstrate of the possible consequences qualitatively. Even with a maximum permissible concentration for specific petroleum hydrocarbons, the knowledge of activity types that cause toxicity increases possibilities for making more correct plans to eliminate the spill consequences.

This work shows that oil radioactivity is a significant environmental risk factor for oil spills. Sediments bind the bulk of oil radionuclides, which then migrate with them and with water masses in small part. Studies of migration of radioactive substances in an aqueous medium carried out for other situations may be used for analysing the migration of oil spill radionuclides. It is shown that the monitoring system for the early detection of oil spills and for monitoring the spill in the postemergency periods is most effective if the remote (fluorescence lidar) and contact methods are used together.

An appreciable part of the results summarized in this paper is presented more fully in other publications by the authors (Barenboim 2010, Barenboim et al. 1998, 2011, 2013a, 2013b).

\section{REFERENCES}

Avandeeva, O., et al. (2014) Patent Numbers: RU2521246-C1; RU2522821-C1

Barenboim. G. (2010) Evaluation of biological hazards of organic xenobiotics in the monitoring of water obiects (problems and ways of their solutions). Int. Meeting: Risk management in aquatic systems: the influence of anthropogenic and climatic changes. Ontario, Canada, 14 pp. (electronic version).

Barenboim. G.. et al. (2013a) On the problems of water quality in Russia and some approaches to their solution. In: Understanding Freshwater Oualitv Problems in a Changing World. Proceedings of H04, IAHS-IAPSO-IASPEI Assembly, Gothenburg, Sweden, July 2013, 77-86. IAHS Publ. 365, Wallingford, UK.

Barenboim. G.. et al. (2013b) Development of a svstem for the early detection and monitoring of oil spills on water bodies with a glance to its use in the Arctic zone. In: Proceedings of the 36th AMOP Technical Seminar on Environmental Contamination and Response, Canada, 565-590.

Barenboim, G. and Saveka A. (2012) New methodological aspects of assessment of biological hazard of oil spill. Proceedings of the Thirty-fifth AMOP Technical Seminar on Environmental Contamination and Response, Environment Canada, Ottawa, 13-30. 
Barenboim, G., Saweka, A. and Chiganova, M. (2011) New methods for assessing of ecological risk of individual hydrocarbons in emergency oil spills (in connection with the problem of environmental risk management). Proceedings of International Workshop Environmental Forensics, Tbilisi, Georgia, September, 157-163.

Barenboim, G.M., Venitsianov, E.V. and Danilov-Danilyan, V.I. (2009) Sustainability: water and oil. Water: Chemistry and Ecology, 6, 2-8 (in Russian).

Barenboim, G.M., et al. (2006) Problems of prevention and mitigation of emergency spills, leakages and unauthorized discharges of oil and oil products (statistical analysis of literary sources). Proceedings of Seventh International Congress "Water: Ecology and Technology", ECWATECH, Moscow, May 30-June 2, 384-385 (in Russian).

Barenboim. G.. Ercev. G.N. and Taskaev, A.I. (2000) Experience of Oil Spill Response in Usinsk District of the Komi Republic, Syktyvkar, 182 p. (in Russian).

Barenboim, G.M., et al. (1998) Automated Systems for Early Detection and Oil Spill Monitoring on Water Bodies. Sarov Publishers, Moscow, VNIIEF, SCHM, 107 p. (in Russian).

Belyaev, V.R., et al. (2013) Using Chernobyl-derived ${ }^{137} \mathrm{Cs}$ to document recent sediment deposition rates on the River Plava floodplain (Central European Russia). Hydrological Processes, 27 (6), 781-794.

Blokov, I. (2011) Overview of pipe leaks and volumes of oil spills in Russian. Greenpeace Russia home page at http://www.greenpeace.org/russia/Global/russia/report/Arctic-oil/Oil_spills.pdf

Golosov, V.N., Belyaev, V.R. and Markelov, M.V. (2013) Application of Chernobyl-derived ${ }^{137}$ Cs fallout for sediment redistribution studies: lessons from European Russia. Hydrological Processes, 27 (6), 807-821.

National Report on Environmental Protection of the Russian Federation, Ministry of Natural Resources and Environmental Protection of Russian Federation (2009) 523 pp. (Rus) from http://www.mnr.gov.ru/regulatory/detail.php?ID=98694

Nemirovskaya, I.A., Brekhovskikh, V.F. and Kazmiruk, T.N. (2009) Origin of hydrocarbons in bottom sediments of the Ivankovo Reservoir. Water Resources 36 (3), 337-344,

Poroikov, V. and Filimonov, D. (2005) PASS: Prediction of biological activity spectra for substances. In: Predictive Toxicology, 459-478. Taylor \& Francis.

Poroikov, V. and Filimonov, D. (2006) Prediction of biological activity spectra for organic compounds Russian Chemical Journal 2, 66-75 (Rus).

Safarov, A.M., et al. (2005) Specific localization of oil pollution on rivers related accident consequences underwater oil pipeline. Oil and Gas Business 1. http://ogbus.ru/authors/SafarovAM/SafarovAM_1.pdf. 